\title{
Moniliformediquinone as a potential therapeutic agent, inactivation of hepatic stellate cell and inhibition of liver fibrosis in vivo
}

\author{
Tsui-Hwa Tseng ${ }^{1,2}$, Wea-Lung Lin ${ }^{3}$, Zi-Hui Chen ${ }^{1}$, Yean-Jang Lee ${ }^{4}$, Ming-Shiun Shie ${ }^{5}$, Kam-Fai Lee ${ }^{6}$, \\ Chien-Heng Shen ${ }^{7,8^{*}}$ and Hsing-Chun Kuo ${ }^{9,10^{*}}$
}

\begin{abstract}
Background: Moniliformediquinone (MFD), a phenanthradiquinone in Dendrobium moniliforme, was synthesized in our laboratory. Beyond its in vitro inhibitory effects on cancer cells, other biological activity of MFD is unknown. The purpose of the present study was to investigate the effects of MFD on hepatic fibrogenesis in vitro and in vivo.

Methods: Hepatic stellate HSC-T6 was cultured. Cell viability assay and western blot analyses were performed. Male ICR mice were evaluated on $\mathrm{CCl}_{4}$-induced hepatotoxicity using both histological examination and immunohistochemical staining.

Results: First, in vitro study showed that the synthesized MFD effectively attenuated the expression of transforming growth factor- $\beta 1$ (TGF- $\beta 1$ ), connective tissue growth factor (CTGF), a-smooth muscle actin (a-SMA), and type I collagen (COL-1), which modulated the hepatic fibrogenesis. Furthermore, MFD reduced the phosphorylation of p65 NFKB in HSC-T6 cells. In vivo, liver fibrosis was induced by $\mathrm{CCl}_{4}$ twice a week for 10 weeks in mice. The administration of the MFD was started after 1 week of $\mathrm{CCl}_{4}$ thrice-weekly; the MFD significantly reduced plasma aspartate transaminase (AST) and lactose dehydrogenase (LDH) as well as hepatic hydroxy-proline, a-SMA, and COL-1 expression in $\mathrm{CCl}_{4}^{-}$ treated mice. Pathological analysis showed that the MFD alleviated $\mathrm{CCl}_{4}$-induced hepatic inflammation, necrosis and fibrosis. These results suggest that MFD possesses therapeutic potential for liver fibrosis.
\end{abstract}

Conclusions: The synthesized MFD exhibits anti-fibrotic potential by inactivation of HSCs in vitro and decreases mouse hepatic fibrosis in vivo. Further investigation into their clinical therapeutic potential is required.

Keywords: Moniliformediquinone, Hepatic fibrosis, $\mathrm{CCl}_{4}$-treated mice

\section{Background}

Liver cancer is usually an aggressive malignant disease with a poor prognosis. Although recent advances have been made in the diagnosis and treatment of tumors, the development of clinical metastasis remains a significant cause of mortality from this disease. Accordingly, hepatic fibrosis represents the final pathological outcome for the majority of chronic liver insults [1-3]. Untreated fibrosis

\footnotetext{
*Correspondence: gi2216@adm.cgmh.org.tw; guscsi@gmail.com

${ }^{8}$ Department of Hepato-Gastroenterological, Chang Gung Memorial Hospital, Chiayi, Taiwan

${ }^{9}$ Institute of Nursing and Department of Nursing, Chang Gung Institute of Technology, Chia-Yi Campus, Chiayi, Taiwan

Full list of author information is available at the end of the article
}

may progress to liver cirrhosis, ultimately leading to organ failure, hepatoma and death $[4,5]$. Unfortunately, effective clinical therapies are still lacking. Liver fibrosis is a progressive pathological process as part of the wound healing and tissue remodeling mechanism in response to chronic liver insults ranging from viral infections to various toxins [5, 6]. During liver fibrosis, excessive extracellular matrix (ECM) is produced and accumulated, leading to liver dysfunction and irreversible cirrhosis $[7,8]$. Hepatic stellate cells (HSCs) have been identified as the principle cellular source of this ECM, even though several other cell types were also recruited to the damaged lesions and differentiated to fibroblastic cells. After acute liver injury and in chronic liver disease, quiescent HSCs 
become activated and transdifferentiate into myofibroblast-like cells characterized by several key phenotypic changes, such as producing excessive extracellular matrix (ECM) including type I collagen (COL- 1$)$ and $\alpha$-smooth muscle actin $(\alpha-S M A)$. Activated HSCs perpetuate their own activation through several autocrine loops, including the secretion of transforming growth factor- $\beta 1$ (TGF- $\beta 1$ ) and connective tissue growth factor (CTGF) [9]. Therefore, the modulation function of activated HSCs has been proposed as a therapeutic strategy against hepatic fibrosis, for instance, decreasing proliferation of HSCs and reducing production of ECM and cytokines.

Accordingly, hepatotoxins cause liver damage characterized by varying degrees of hepatocyte degeneration and cell death, such as ethanol, acetaminophen, and carbon tetrachloride $\left(\mathrm{CCl}_{4}\right)$. For instance, $\mathrm{CCl}_{4}$ impairs hepatocytes directly by altering the permeability of the plasma, lysosomal, and mitochondrial membranes. In addition, $\mathrm{CCl}_{4}$-induced liver fibrosis shows many characteristics with human fibrosis of different etiologies [10]. Furthermore, $\mathrm{CCl}_{4}$-induced hepatic injury has been extensively used in animal models to evaluate the therapeutic potential of drugs. On the other hand, plants of the Dendrobium genus (Orchidaceae) are used in traditional herbal medicines in Asia, and studies have shown that they contain a wide variety of medicinal properties [11-13]. Moniliformediquinone (2,6-dimethoxy-1,4,5,8phenanthradiquinone; MFD) (Fig. 1), collected by Chang et al. has been isolated from stems of Dendrobium monilifore (L.) Sw. in Taiwan and has been found to have anti-inflammation and anticancer effects [14]. In addition, our previous study of synthesized MFD showed that synthesized MFD could induce in vitro and in vivo antitumor activity through a glutathione-involved DNA damage response and mitochondrial stress in human hormone refractory prostate cancer [15]. Other biological activities of MFD are unknown. In the present study, the anti-hepatic fibrosis potential of synthesized MFD was evaluated using HSC-T6, an activated HSC cell line, and a mouse model of $\mathrm{CCl}_{4}$-induced hepatic injury. Further study aimed to investigate the effect of synthesized MFD on the expression of activated HSC-T6 markers and fibrosis-related proteins and its relationship with the expression of TGF- $\beta 1, \alpha-S M A$, and COL- 1 . Finally, pathological analysis showed that the synthesized MFD could possess therapeutic potential for liver fibrosis.

\section{Methods}

\section{Chemicals}

Dulbecco's modified Eagle's medium (DMEM), phosphate-buffered saline (PBS), fetal bovine serum, $L$-glutamine, penicillin/streptomycin (PS), and trypsin-EDTA were purchased from GIBCO Ltd. (Grand Island, NY,

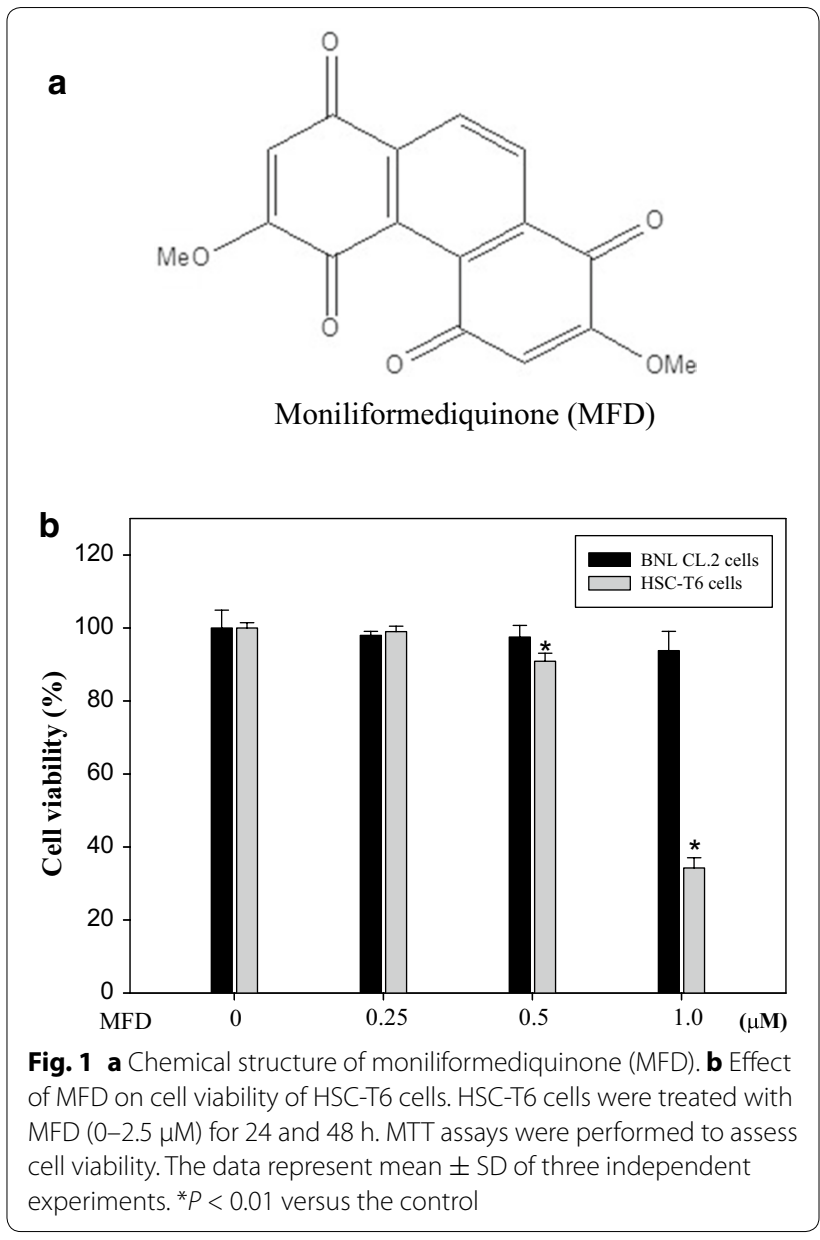

USA). Anti-CTGF, $\alpha$-SMA, and $\alpha$-tubulin antibodies were provided from Santa Cruz Biotechnology (Santa Cruz, CA). Anti-TGF- $\beta 1$ was obtained from Cell signaling Technology (Beverly, MA). Other chemical reagents were purchased from Sigma-Aldrich.

The 2,6-dimethoxy-1,4,5,8-phenanthrenetetrone, moniliformediquinone (MFD), was prepared as previous procedure [16]. Melting point and ${ }^{1} \mathrm{H}$ and ${ }^{13} \mathrm{C}$ NMR spectra of the synthetic MFD are in agreement with those reported for the natural product [14]. Thus, the drug of synthetic MFD is $>95 \%$ purity $\left({ }^{13} \mathrm{C}\right.$ NMR peak purity test) for following bioassay. The TdT-mediated dUTP Nick End Labeling (TUNEL) kits were purchased from Roche (Germany).

\section{Cell culture and MTT assay}

The immortalized hepatic stellate cell line (HSC-T6) and murine liver cell (BNL CL.2) were maintained in Dulbecco's modified Eagle's medium (DMEM) plus $10 \%(\mathrm{v} / \mathrm{v})$ fetal bovine serum, penicillin-streptomycin $(100 \mathrm{IU} / \mathrm{mL}-100 \mu \mathrm{g} / \mathrm{mL})$, and incubated at $37{ }^{\circ} \mathrm{C}$ in a $5 \% \mathrm{CO}_{2}$ humidified atmosphere. Cell viability was determined using MTT assay. In brief, cells 
(2-5 $\times 10^{4}$ cells/well) were seeded in 24-well culture plates and exposed to different concentrations of moniliformediquinone for $24 \mathrm{~h}$. Next, the medium was changed and the cells were incubated with MTT (5 mg/ $\mathrm{mL}$ ) for $4 \mathrm{~h}$. Finally, the absorbance of the formazan product was measured at a wavelength of $570 \mathrm{~nm}$ on an ELISA reader [17].

\section{Preparation of total cell extracts and immunoblots analysis} Cells $\left(1 \times 10^{6}\right.$ cells/well $)$ were seeded in $10-\mathrm{cm}$ dishes in the presence of the MFD. The cells were collected by trypsin-EDTA and lysed in RIPA buffer $(50 \mathrm{mM}$ Tris$\mathrm{HCl}, 1 \mathrm{mM}$ EDTA, $150 \mathrm{mM} \mathrm{NaCl}, 1 \% \mathrm{NP}-40)$ containing protease inhibitors. After mixing for $30 \mathrm{~min}$ at $4{ }^{\circ} \mathrm{C}$, the mixtures were centrifuged $(10,000 \times g)$ for $10 \mathrm{~min}$ at $4{ }^{\circ} \mathrm{C}$ and the supernatants were collected as whole-cell extracts. The protein content was determined using the Bio-Rad protein assay reagent and bovine serum albumin as a standard. An equal amount of protein from the total cell extracts was boiled for $8 \mathrm{~min}$. The extracts were separated by SDS-polyacrylamide gels and transferred to a NC membrane (Whatman). The blots were blocked in $5 \%$ non-fat dry milk/PBS for $1 \mathrm{~h}$ at room temperature. The blots then were incubated overnight with primary antibodies, followed by horseradish peroxidase-conjugated goat anti-mouse (or rabbit) IgG for $1 \mathrm{~h}$. The immunoreactive bands were revealed by enhanced chemiluminescence with a commercially available ECL kit [18].

\section{Animals}

Male ICR mice (body weight 18-22 g) were purchased from GlycoNex Inc. (Taiwan) and maintained in cage housing in a specifically designed pathogen-free isolation facility with a 12/12 h light/dark cycle. Animal care and the general protocols for animal use were approved by the Institutional Animal Care and Use Committee of Chung Shan Medical University Animal Ethics Research Board. All mice of $\mathrm{CCl}_{4}$-treated alone and combined MFD administration group were given $0.1 \mathrm{~mL} /$ mice of $\mathrm{CCl}_{4}\left(20 \% \mathrm{CCl}_{4}\right.$ in olive oil $)$ via intragastric twice a week for 10 weeks. The mice were intraperitoneal injected with 0.1 and $0.5 \mathrm{mg} / \mathrm{kg}$ of MFD thrice a week. Those in control and MFD-treated alone groups were given equal volume of olive oil. The mice were divided randomly into five groups of eight mice each. Then, the mice were sacrificed $24 \mathrm{~h}$ after the last injection. The livers were divided into two portions (1) preserved in $10 \%$ formalin for histological examination, (2) frozen for immunoblotting analysis at $-70{ }^{\circ} \mathrm{C}$.

\section{Biochemical assays}

Blood was obtained by intra-cardiac puncture from mice. Serum was separated and levels of alanine aminotransferase (AST) and lactate dehydrogenase (LDH) were measured using standard enzymatic assay kits. Each assay is a colorimetric assay with detection of a highly colored end product measured at $490-520 \mathrm{~nm}$. The absorbance of each end product is proportional to the enzyme's activity [19].

Liver samples were lysed in radioimmunoprecipitation assay (RIPA) buffer containing $50 \mathrm{mM}$ Tris-HC pH 7.4, $150 \mathrm{mM} \mathrm{NaCl}, 1 \% \mathrm{NP}-40,0.5 \%$ sodium deoxycholate, $0.1 \%$ SDS, $2 \mathrm{mM}$ phenylmethylsulfonyl fluoride, $1 \mathrm{mM}$ sodium orthovanadate, and $2 \mu \mathrm{g} / \mathrm{mL}$ of each leupeptin and pepstatin. Volume equivalent to $50 \mu \mathrm{g}$ of proteins was analyzed by western immunoblotting assay as previous description.

\section{Histopathological analysis}

Liver tissues from each mouse were rapidly removed, fixed in $10 \%$ neutral-buffered formalin, and processed routinely. Paraffin-embedded sections were cut into $4 \mu \mathrm{m}$ thick sections. The sections were stained with hematoxylin and eosin (H\&E) and with Masson's trichome for collagen fibers [20].

\section{Immunohistochemistry}

Immunohistochemistry (IHC) staining was performed using a biotinylated secondary antibody (Vectastain Universal Elite $A B C$ Kit, Burlingame, CA, USA). Monoclonal rabbit antibodies against peroxiredoxin 2 and alpha-1-antiproteinase were diluted at a ratio of 1:100. The omission of primary antibodies was used as the negative control. For three slides, cytoplasm that was stained brown was scored as positive. The expression of hydroxy-proline, $\alpha$-SMA and COL-1 were quantitatively evaluated using an Olympus CX31 microscope (Tokyo, Japan) with the Image-pro Plus medical image analysis system. Digital images were captured using a digital camera (Canon A640, Tokyo, Japan). The positive area and optical density (OD) of hydroxyproline, $\alpha$-SMA and COL-1 positive cells were determined by measuring three randomly selected microscopic fields (400× magnification) for each slide. The IHC index was defined as the average integral optical density (AIOD) $(\mathrm{AIOD}=$ positive area $\times \mathrm{OD} /$ total area $)[21]$.

\section{Statistical analysis}

All experiments were carried out in triplicate, and data were expressed as mean $\pm \mathrm{SD}$. One-way analysis of variance (ANOVA) and the Duncan test were carried out to determine significant differences of multiple comparisons. Significance was defined as a $P$ value of less than 0.05 [19].

\section{Results}

Cytotoxicity of MFD in HSC-T6 and BNL CL.2 cells

Figure 1 shows the effects of various concentrations of MFD on activated HSCs (HSC-T6) and normal murine 
liver cells (BNL CL.2). After treatment for $48 \mathrm{~h}$. MFD showed a cytotoxicity effect on HSC-T6 cells above $0.5 \mu \mathrm{M}$ concentrations whereas the applied concentration showed noncytotoxicity on BNL CL. 2 cells.

\section{Effect of MFD on the expression of TGF- $\beta$, CTGF, $\alpha-S M A$, COL-1 in HSC-T6 cells}

Transforming growth factor- $\beta 1$ (TGF- $\beta 1$ ) is a major fibrotic growth factor in liver fibrosis [9]. CTGF is selectively induced by TGF- $\beta$ in a fibroblastic cell type and plays a key role in the overproduction of ECM in activated HSCs. Therefore, we determined the levels of TGF$\beta 1$ and CTGF after treatment with MFD in HSC-T6 cells using western blot analysis. The results showed that MFD significantly decreased the protein level of TGF- $\beta 1$ and CTGF (Fig. 2a). In addition, the most striking biological consequences of activated HSCs are the marked accumulation of $\alpha$-SMA and the dramatic increase in collagen depositions. MFD reduced the levels of $\alpha$-SMA and COL-1 after treatment with MFD in HSC-T6 cells as compared with the control (Fig. 2a). Furthermore, MFD inhibited the phosphorylation of p65 NFkB (Fig. 2a), which has been suggested to be associated with the regulation of TGF- $\beta 1$ expression [22]. To confirm the important role of TGF- $\beta 1$ affected by MFD, TGF- $\beta 1$ was added to promote the expression of CTGF, $\alpha$-SMA, and COL1. As shown in Fig. 2b, MFD reduced the expression of CTGF, $\alpha$-SMA, and COL-1, which were mediated by TGF- $\beta 1$.

\section{Inhibitory effect of MFD on $\mathrm{CCl}_{4}$-induced hepatotoxicity in mice}

In order to evaluate hepatic tissue damage, serum enzyme levels of $\mathrm{LDH}$ and AST with/without $\mathrm{CCl}_{4}$-treated mice were determined by using standard enzymatic kits. As shown in Fig. 3, serum LDH and AST activity in mice treated with MFD alone did not significantly differ from that of the control group. AST and LDH activity of all $\mathrm{CCl}_{4}$-treated mice increased significantly as compared with that of the control group after the end of the experiment $(P<0.001)$. However, administration of the MFD significantly suppressed the $\mathrm{CCl}_{4}$-induced increase of LDH and AST activity, respectively $(P<0.01, P<0.001)$.

\section{MFD inhibits $\mathrm{CCl}_{4}$-induced TGF- $\beta 1$, $\alpha$-SMA and COL-1 expression in mouse liver}

The TUNEL assay results are shown in Fig. 4. Global immunoreactivity to apoptosis was localized primarily within liver tissue in $\mathrm{CCl}_{4}$ mouse. Quantitative examination of hepatocyte pathology showed that the number of normal hepatocytes present in the $\mathrm{CCl}_{4}$ treatment group was lower than the number of normal hepatocytes present in the control groups (control group $=5 \pm 1$; $\mathrm{CCl}_{4}$ treatment group $=65 \pm 3 ; 0.1 \mathrm{mg} / \mathrm{kg}$ MFD treated $\mathrm{CCl}_{4}=30 \pm 3 ; 0.5 \mathrm{mg} / \mathrm{kg}$ MFD treated $\mathrm{CCl}_{4}=15 \pm 3$, $P<0.05)$. We employed immunohistochemistry to examine liver hydroxy-proline protein expression in the hepatocyte of the untreated control and MFD alone group, the $\mathrm{CCl}_{4}$ group and the two $\mathrm{CCl}_{4}+\mathrm{MFD}$ groups, which acts as an index of oxidative damage in hepatic fibrosis, was measured in order to investigate the therapeutic effect of MFD. A significant reduction in hydroxy-proline was found in the $\mathrm{CCl}_{4}+\mathrm{MFD}$ groups compared to the $\mathrm{CCl}_{4}$ group. Significantly decreased expression of $\alpha$-SMA, and COL-1 proteins were found in the MFD groups compared to the $\mathrm{CCl}_{4}$ group, $P<0.05$ (Fig. 4).

\section{Histopathological examination}

As shown in Fig. 5, in vehicle control and MFD-onlytreated mice, liver sections showed normal hepatic cells, i.e., with a well-preserved cytoplasm, a prominent nucleus, and a central vein. The livers of $\mathrm{CCl}_{4}$-intoxicated mice revealed moderate to severe hepatocellular vacuolization, hepatic necrosis, and inflammatory cell filtration. Against the pathological changes, the lesions of the $0.5 \mathrm{mg} / \mathrm{kg}$ MFD-treated mice were of a much milder degree compared with the lesions observed in the group treated with $\mathrm{CCl}_{4}$ alone. In addition, the collagen of fibrotic tissues showed a blue color when stained by Masson's trichrome. There was no fibrosis in either the control group or the group treated with MFD alone. In contrast, a large number of blue collagen fibers were observed in the $\mathrm{CCl}_{4}$-treated mouse (Fig. 5). In the $0.5 \mathrm{mg} / \mathrm{kg}$ MFD-treated group, the extent and area of the collagen fibers was apparently reduced (Table 1 ).

\section{Discussion}

Hepatic stellate cells (HSC) are considered to play a key role in the pathogenesis of liver fibrosis. During liver fibrogenesis, HSCs are activated and acquire a myofibroblast-like phenotype that is accompanied by increased proliferation and extracellular matrix synthesis [23, 24]. Therefore, suppression of HSC activation has been proposed as a therapeutic target against hepatic fibrosis. In the present study, synthesized MFD was measured for its anti-fibrotic activities by assessing the effect on the suppression expression of fibrotic-associated protein. $\alpha$-SMA is a definite marker of transdifferentiation of stellate cells. The experimental data showed that MFD reduced $\alpha$-SMA expression in HSC-T6 cells and in the liver of the $\mathrm{CCl}_{4}$-treated mouse (Figs. 2, 4). Furthermore, collagens such as COL-1 are the main components of the ECM, and the main collagen-producing cells in the liver are HSCs. The present study found that MFD decreased 
a

$\begin{array}{llllll}\text { MFD } & 0 & 0.1 & 0.25 & 0.5 & (\mu \mathbf{M})\end{array}$
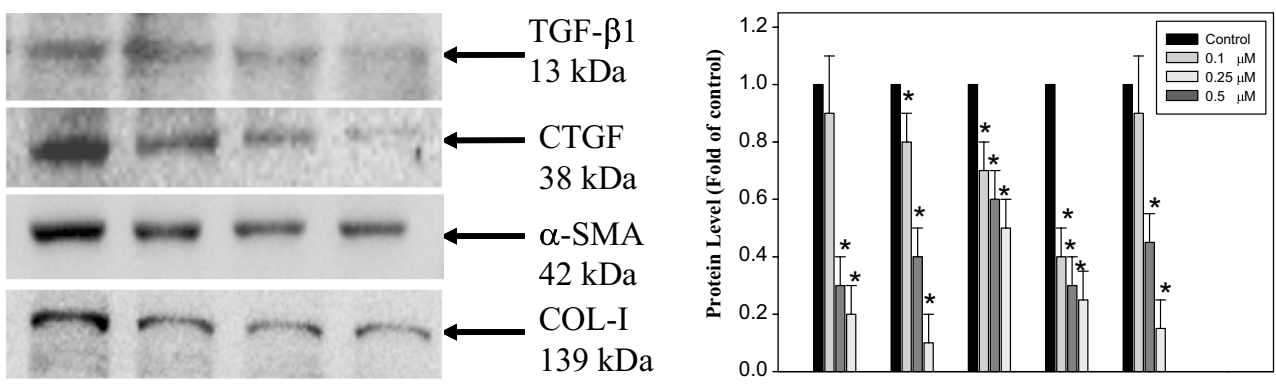

$139 \mathrm{kDa}$

TGF- $\beta 1 \quad$ CTGF $\quad \alpha$-SMA COL-I p-p65 NFkB

p-p65 NFкB

$65 \mathrm{kDa}$

$\longrightarrow$

$42 \mathrm{kDa}$

b

TGF- $\beta$
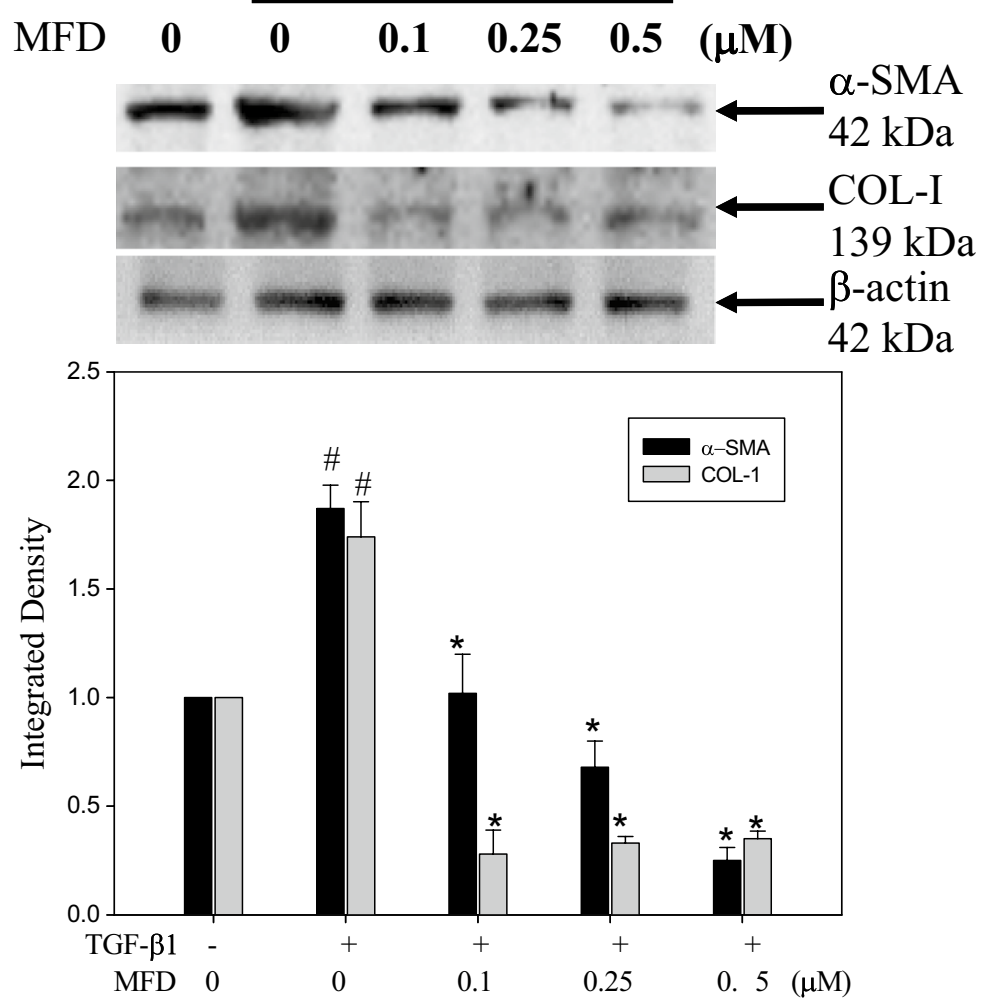

Fig. 2 Effect of MFD on the expression of activated HSC-T6 markers and fibrosis-related proteins. HSC-T6 cells were treated with various concentrations of MFD for 48 h; then total cell lysates were tested for (a) TGF- 31, CTGF, a-SMA, COL-1 and p-p65 NFkB by western blot analysis. b HSC-T6 cells were treated with TGF- $\beta 1(2 \mathrm{ng} / \mathrm{mL})$ alone or in combination with different concentrations of MFD for $48 \mathrm{~h}$; then total cell lysates were analyzed by western blot analysis against anti-CTGF, anti-a-SMA, anti-COL-1, and anti- $\beta$-actin as an internal control. Quantification of band intensity relative to a-tubulin is shown below the western blot. The quantitative data were presented as the mean of three repeats from one independent experiment. The data were presented as mean \pm SD of three independent experiments. ${ }^{*} P<0.05$ versus control. ${ }^{*} P<0.05$, versus TGF- $\beta 1$-treated alone 


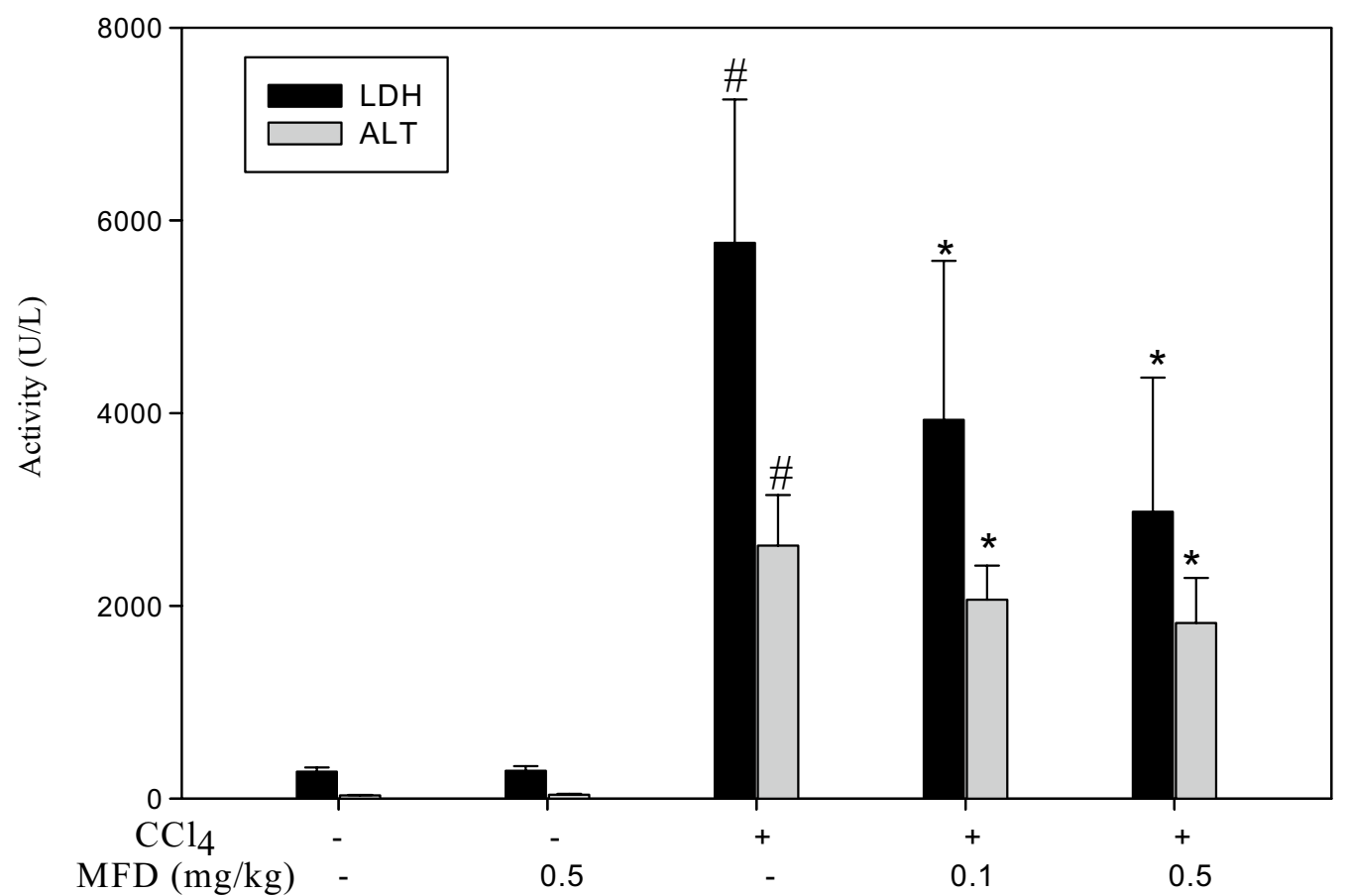

Fig. 3 Effects of MFD on serum AST and LDH in $\mathrm{CCl}_{4}$-treated mice. The data for serum $\mathrm{LDH}$ and AST are presented as mean \pm SD from six mice per group. ${ }^{\#} P<0.05$, as compared to the control group; ${ }^{*} P<0.05$, as compared to the $\mathrm{CCl}_{4}$-treated group

COL-1 expression in HSC-T6 cells and in the liver of the $\mathrm{CCl}_{4}$-treated mouse (Figs. 4, 5). These results showed that MFD can inhibit HSCs activation. In addition, it first demonstrated, in vitro and in vivo, an anti-fibrotic effect of MFD, which has been isolated from the Dendrobium monilifore stem. Moreover, phenanthrenes from the Dendrobium nobile stem have previously been shown to exhibit anti-fibrotic potential [13]. Consistent with these findings, the Dendrobium species is thought to be useful for developing therapeutic agents for the treatment of hepatic fibrosis.

Many studies have evaluated candidate anti-fibrosis factors or reagents by assessing their impact on TGF$\beta$-induced collagen and $\alpha$-SMA expression in fibroblasts. For instance, TGF- $\beta 1$ is a pleiotropic cytokine involved in the activation of HSCs, the main producers of ECM components in the liver [25]. In general, TGF$\beta 1$ induces the expression of type I collagen and inhibits apoptosis of HSCs. It is also suggested that TGF- $\beta 1$ can up-regulate the platelet-derived growth factor beta $($ PDGF- $\beta$ ) receptor, resulting in a proliferation response in activated HSCs [26]. As shown in Fig. 3, MFD inhibited DNA synthesis in correlation with reducing the expression of TGF- $\beta 1$. There are many regulators involved in the inflammation-fibrosis process, and the NFKB signaling pathway appears to play a critical role in liver homeostasis, pathophysiology, and regulation of inflammation-fibrosis [27]. $\mathrm{NF}_{K} B$ is found in activated HSC [28], where it is involved in upregulating proinflammatory gene encoding adhesion molecules, chemokines, and cytokines such as TGF- $\beta 1$. Our study found that MFD inhibited the phosphorylation of p65 NFkB and the expression of TGF- $\beta 1$ (Fig. $2 a, b$ ). $\mathrm{NF} \kappa \mathrm{B}$ was also involved in the protection of HSC from apoptosis. Suppression of NFKB may increase apoptosis of HSC. As shown in Fig. 2b, MFD can reduce the TGF- $\beta 1$-stimulating expression of $\alpha$-SMA, COL- 1 , and CTGF, which are downstream of TGF- $\beta 1$. These data imply that MFD possesses an anti-fibrogenesis effect by inhibiting HSCs activation associated with blocking the NFKB signaling pathway and reducing TGF- $\beta 1$ expression. The molecular mechanism of the signaling pathway regulated by MFD in HSC needs further clarification.

Hepatic fibrosis, a leading cause of morbidity and mortality worldwide, is usually associated with chronic liver disease. Hepatic fibrosis can develop into cirrhosis within 1-10 years [29]. Thereafter, blocking the progression of fibrosis may be an efficacious strategy to survival. As a consequence, $\mathrm{CCl}_{4}$-induced hepatic 


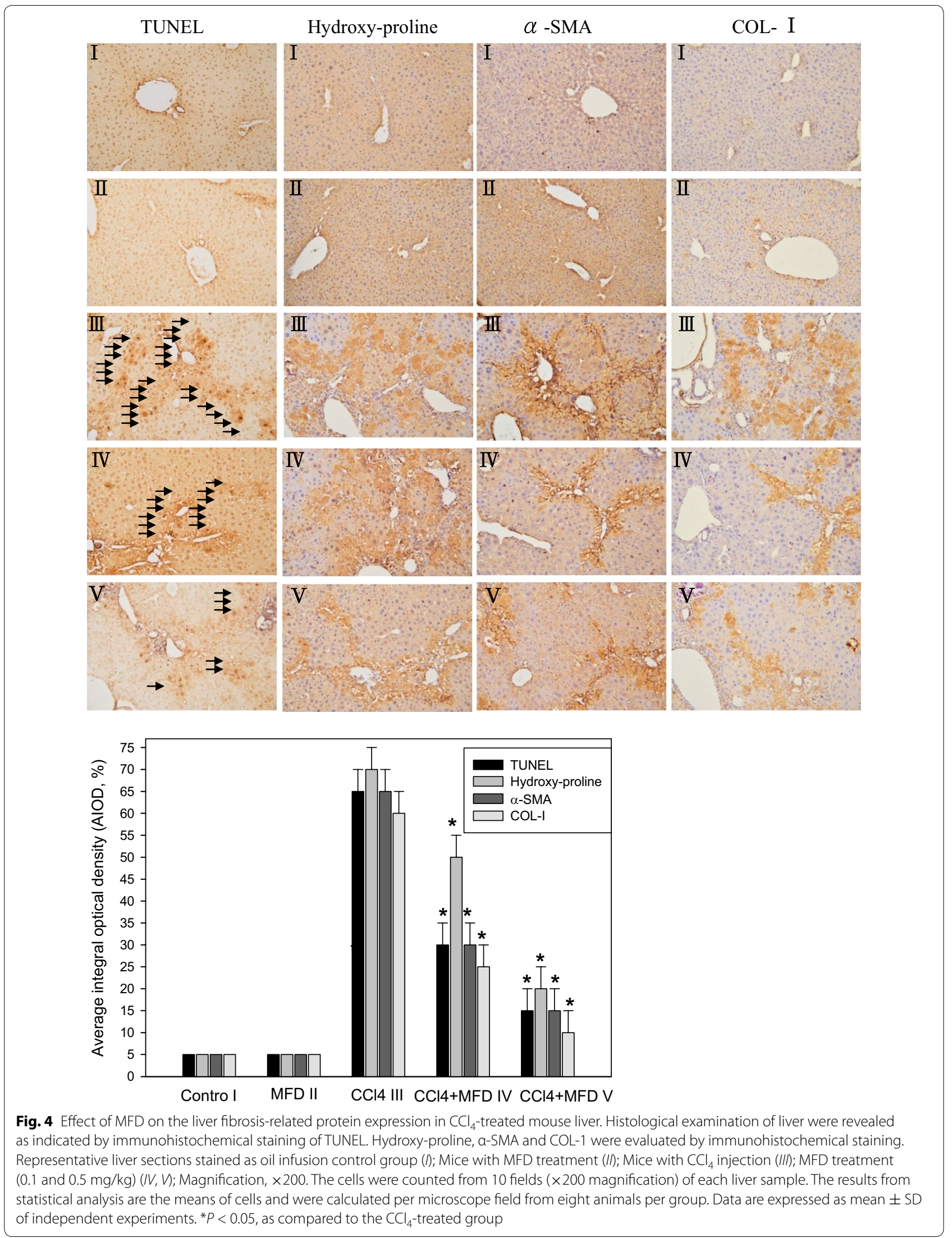



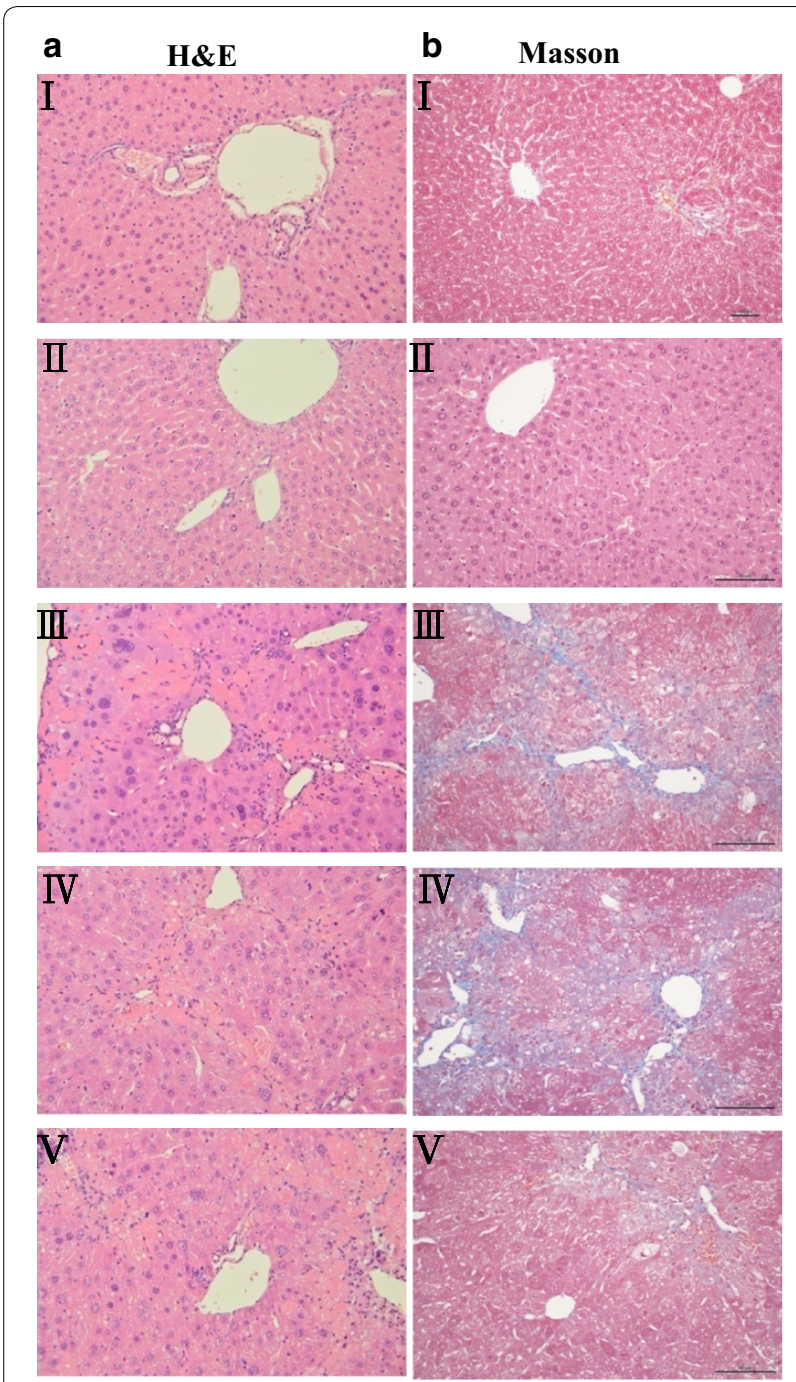

Fig. 5 Effect of MFD on histological changes in the liver of $\mathrm{CCl}_{4}{ }^{-}$ treated mice. Lliver sections stained as oil infusion control group (I); mice with MFD treatment (II); mice with $\mathrm{CCl}_{4}$ injection (III); MFD treatment ( 0.1 and $0.5 \mathrm{mg} / \mathrm{kg})(\mathrm{IV}, \mathrm{V})$; the section of mouse liver was stained with a hematoxylin-eosin or $\mathbf{b}$ Masson's trichrome (magnification $\times 200$ ) injury is an experimental model used for drug screening [30]. In addition, AST and LDH are enzymatic indicators of tissue damage by toxicants or disease condition, and abnormal levels of AST and LDH are important to pathology and toxicology. According to our in vivo study, administration of MFD significantly reduced the level of AST and LDH as compared with the group treated with $\mathrm{CCl}_{4}$ alone (Fig. 3). In addition, MFD inhibited $\mathrm{CCl}_{4}$-induced hepatic fibrotic factor expression such as hydroxy-proline, $\alpha$-SMA, and COL-1 (Fig. 4). Histopathological examination showed that $0.5 \mathrm{mg} /$ $\mathrm{kg}$ MFD apparently decreased $\mathrm{CCl}_{4}$-induced hepatic inflammation, necrosis, and fibrosis (Fig. 5). These results demonstrated that the synthesized MFD can block $\mathrm{CCl}_{4}$-induced hepatic damage and fibrotic progression. Based on our results, it makes possible that cultured HSC underwent a rapid and persistent induction NF-kB, while the inhibition of NF-kB as well as CTGF, $\alpha$-SMA and COLI by MFD were required in a dose-dependent. In this study, we investigated MFD has an inhibitory effect on the $\mathrm{CCl}_{4}$ model of hepatocyte injury that is cytotoxic to serious fibrotic liver in vivo. Further investigation is required to better understand whether when $\mathrm{CCl}_{4}$ infusion in rats were established as model of liver dysfunction and fibrogenesis, treatment with MFD induced a significant dose-dependent decrease in liver fibrosis for a period of time points. These results provide insights into the therapeutic activity of MFD, which thus may be promising candidates for the treatment of liver injury diseases such as hepatic fibrosis.

\section{Conclusions}

In summary, this study concludes that the synthesized MFD exhibits anti-fibrotic potential by inactivation of HSCs in vitro and decreases mouse hepatic fibrosis in vivo. Further investigation into their clinical application is required.

Table 1 MFD exhibits anti-fibrotic potential by decreasing mouse hepatic fibrosis in vivo

\begin{tabular}{lllll}
\hline & Inflammation & Degeneration & Hepatocyte necrosis & Fibrosis \\
\hline Control & - & - & - & - \\
MFD alone & - & & - & + \\
$C C_{4}$ alone & +++ & ++ & ++ & +++ \\
$C C_{4}+$ MFD $(0.1 \mathrm{mg} / \mathrm{kg})$ & +++ & ++ & +++ & ++ \\
$C \mathrm{Cl}_{4}+\mathrm{MFD}(0.5 \mathrm{mg} / \mathrm{kg})$ & ++ & + & + & + \\
\hline
\end{tabular}




\section{Abbreviations}

HSCs: hepatic stellate cells; BSA: bovine serum albumin; DMSO: dimethylsulfoxide; FBS: fetal bovine serum; ECM: extracellular matrix; CTGF: connective tissue growth factor; a-SMA: a-smooth muscle actin; COL-1: type I collagen; NF-kB: nuclear factor-kB; PBS: phosphate buffered saline; TGF- $\beta$ : transforming growth factor- $\beta$; AST: aspartate transaminase; LDH: lactose dehydrogenase.

\section{Authors' contributions}

T-HT: Provision of study material, collection and assembly of data and manuscript writing; Z-HC and Y-JL: Design, collection, assembly of data and Chemical; M-CH: Conception, collection, and assembly of data; W-LL: Provision of study material or animals and histopathological evaluation; K-FL: Provision of study material, collection, and assembly of data; C-HS and H-CK: Conception and design, financial support, administrative support, manuscript writing, final approval of manuscript. All authors read and approved the final manuscript.

\section{Author details}

${ }^{1}$ Department of Medical Applied Chemistry, Chung Shan Medical University, Taichung, Taiwan. ${ }^{2}$ Department of Medical Education, Chung Shan Medical University Hospital, Taichung, Taiwan. ${ }^{3}$ Department of Pathology, Chung Shan Medical University Hospital, Taichung, Taiwan. ${ }^{4}$ Department of Chemistry, National Changhua University of Education, Changhua, Taiwan. ${ }^{5}$ High Quality Biomedical Management \& Consultant Inc., Taichung, Taiwan. ${ }^{6}$ Department of Pathology, Chang Gung Memorial Hospital, Chiayi, Taiwan. ${ }^{7}$ Graduate Institute of Clinical Medical Sciences, College of Medicine, Chang Gung University, Taoyuan, Taiwan. ${ }^{8}$ Department of Hepato-Gastroenterological, Chang Gung Memorial Hospital, Chiayi, Taiwan. ${ }^{9}$ Institute of Nursing and Department of Nursing, Chang Gung Institute of Technology, Chia-Yi Campus, Chiayi, Taiwan. ${ }^{10}$ Chronic Diseases and Health Promotion Research Center, CGUST, Chiayi, Taiwan.

\section{Acknowledgements}

The research was supported by Grants (CSMU-INT-102-16) from Chung Shan Medical University, the Ministry of Science and Technology (MOST 100-2320B-040-006, 101-2113-M-018-002-MY3). This study was supported by Grants BMRPD42, CLRPG8D0112, CMRPF6E0011, CMRPF6E0021 and CMRPF6E0041 from Chang Gung Memorial Hospital-Kaohsiung Medical Center, Chang Gung Memorial Hospital, and Chang Gung University of Science and Technology, Chia-Yi Campus, Taiwan and by the Ministry of Science and Technology, Taiwan (MOST 104-2320-B-255 -003-MY3).

\section{Competing interests}

The authors declare that they have no competing interests and are responsible for the contents of this study.

\section{Availability of data and materials}

All relevant data are within the paper.

\section{Ethics approval and consent to participate}

Animal care and the general protocols for animal use were approved by the Institutional Animal Care and Use Committee of Chung Shan Medical University.

\section{Funding}

This work was supported by the grants from Chung Shan Medical University, the Ministry of Science and Technology, Chang Gung Memorial Hospital, and Chang Gung University of Science and Technology, Chia-Yi Campus, Taiwan. The funders had no role in study design, data collection and analysis, or manuscript preparation.

Received: 13 July 2016 Accepted: 26 August 2016

Published online: 09 September 2016

\section{References}

1. Lotersztajn S, Julien B, Teixeira-Clerc F, Grenard P, Mallat A. Hepatic fibrosis: molecular mechanisms and drug targets. Annu Rev Pharmacol Toxicol. 2005;45:605-28.

2. Friedman SL. Mechanisms of hepatic fibrogenesis. Gastroenterology. 2008;134:1655-69.
3. Tsukada S, Parsons CJ, Rippe RA. Mechanisms of liver fibrosis. Clin Chim Acta. 2006;364:33-60.

4. Thompson AJ, Patel K. Antifibrotic therapies: will we ever get there? Curr Gastroenterol Rep. 2010;12:23-9.

5. Friedman SL. Liver fibrosis—from bench to bedside. J Hepatol. 2003;38:S38-53.

6. Elsharkawy AM, Oakley F, Mann DA. The role and regulation of hepatic stellate cell apoptosis in reversal of liver fibrosis. Apoptosis. 2005; 10:927-39.

7. Bataller R, Brenner DA. Hepatic stellated cells as a target for the treatment of liver fibrosis. Semin Liver Dis. 2001:21:437-51.

8. Hinz B. Formation and function of the myofibroblast during tissue repair. J Invest Dermatol. 2007;3:526-37.

9. Satish L, Gallo PH, Baratz ME, Johnson S, Kathju S. Reversal of TGF- $\beta 1$ stimulation of a-smooth muscle actin and extracellular matrix components by cyclic AMP in Dupuytren's-derived fibroblasts. BMC Musculoskelet Disord. 2011;12:113.

10. Hsu YW, Tsai CF, Chuang WC, Chen WK, Ho YC, Lu FJ. Protective effects of silica hydride against carbon tetrachloride-induced hepatotoxicity in mice. Food Chem Toxicol. 2010;48:1644-53.

11. Song Jl, Kang YJ, Yong HY, Kim YC, Moon A. Denbinobin, a phenanthrene from Dendrobium nobile, inhibits invasion and induces apoptosis in SNU484 human gastric cancer cells. Oncol Rep. 2012;27:813-8.

12. Kim JH, Oh SY, Han SB, Uddin GM, Kim CY, Lee JK. Anti-inflammatory effects of Dendrobium nobile derived phenanthrenes in LPS-stimulated murine macrophages. Arch Pharm Res. 2015;38:1117-26.

13. Yang H, Lee PJ, Jeong EJ, Kim HP, Kim YC. Selective apoptosis in hepatic stellate cells mediates the antifibrotic effect of phenanthrenes from Dendrobium nobile. Phytother Res. 2012;26:974-80.

14. Lin TH, Chang SJ, Chen CC, Wang JP, Tsao LT. Two phenanthraquinones from Dendrobium moniliforme. J Nat Prod. 2001:64:1084-6.

15. Hsu JL, Lee YJ, Leu WJ, Dong YS, Pan SL, Uang BJ, Guh JH. Moniliformediquinone induces in vitro and in vivo antitumor activity through glutathione involved DNA damage response and mitochondrial stress in human hormone refractory prostate cancer. J Urol. 2014;191:1429-38.

16. Thangaraj S, Tsao WS, Luo YW, Lee YJ, Chang CF, Lin CC, Uang BJ, Yu CC, Guh JH, Teng CM. Total synthesis of moniliformediquinone and calanquinone A as potent inhibitors for breast cancer. Tetrahedron. 2011;67:6166-72.

17. Lu CC, Huang WS, Lee KF, Lee KC, Hsieh MC, Huang CY, Lee LY, Lee BO, Teng CC, Shen $\mathrm{CH}$, Tung SY, Kuo HC. Inhibitory effect of erinacines A on the growth of DLD-1 colorectal cancer cells is induced by generation of reactive oxygen species and activation of p70S6K and p21. J Funct Foods. 2016:21:474-84.

18. Kuo HC, Lu CC, Shen CH, Tung SY, Hsieh MC, Lee KC, Lee LY, Chen CC, Teng CC, Huang WS, Chen TE, Lee KF. Hericium erinaceus mycelium and its isolated erinacine A protection from MPTP-induced neurotoxicity through the ER stress, triggering an apoptosis cascade. J Transl Med. 2016;14:78.

19. Tsai JJ, Kuo HC, Lee KF, Tsai TH. Proteomic analysis of plasma from rats following total parenteral nutrition-induced liver injury. Proteomics. 2015;15:3865-74

20. Lee KF, Chen JH, Teng CC, Shen CH, Hsieh MC, Lu CC, Lee KC, Lee LY, Chen WP, Chen CC, Huang WS, Kuo HC. Protective effects of Hericium erinaceus mycelium and its isolated erinacine A against ischemia-injury-induced neuronal cell death via the inhibition of iNOS/p38 MAPK and nitrotyrosine. Int J Mol Sci. 2014;15:15073-89.

21. Shen CH, Tung SY, Huang WS, Lu CC, Lee KC, Hsieh YY, Chang PJ, Liang HF, Chen JH, Lin TH, Hsieh MC, Kuo HC. Exploring the effects of tert-butylhydroperoxide induced liver injury using proteomic approach. Toxicology. 2014;316:61-70.

22. Lin W, Tsai WL, Shao RX, Wu G, Peng LF, Barlow LL, Chung WJ, Zhang $\mathrm{L}$, Zhao $\mathrm{H}$, Jang JY, Chung RT. Hepatitis $C$ virus regulates transforming growth factor $\beta 1$ production through the generation of reactive oxygen species in a nuclear factor KB-dependent manner. Gastroenterology. 2010;138:2509-18.

23. Lee UE, Friedman SL. Mechanisms of hepatic fibrosis. Best Pract Res Clin Gastroenterol. 2011;25:195-206.

24. Friedman SL. Hepatic fibrosis-overview. Toxicology. 2008;254:120-9.

25. Bataller R, Brenner DA. Liver fibrosis. J Clin Invest. 2005:115:209-18. 
26. Shah R, Reyes-Gordillo K, Arellanes-Robledo J, Lechuga CG, HemándezNazara Z, Cotty A, Rojkind M, Lakshman MR. TGF- $\beta 1$ up-regulates the expression of PDGF- $\beta$ receptor mRNA and induces a delayed PI3K- AKTand $\mathrm{p} 70^{\mathrm{S} 6 \mathrm{~K}}$ - dependent proliferative response in activated hepatic stellate cells. Alcohol Clin Exp Res. 2013;37:1838-48.

27. Sun B, Karin M. NF-KB signaling, liver disese and hepatoprotective agents. Oncogene. 2008;27:6228-44.

28. Elsharkawy AM, Wright MC, Hay RT, Arthur MJP, Hughes T, Bahr MJ, Degitz $\mathrm{K}$, Mann DA. Persistent activation of nuclear factor-KB in cultured rat hepatic stellate cells involves the induction of potentially novel Rel-like factors and prolonged changes in the expression of I KB family proteins. Hepatology. 1999;30:761-9.

29. Hernandez-Gea V, Friedman SL. Pathogenesis of liver fibrosis. Annu Rev Pathol Mech Dis. 2011;6:425-56.

30. Domitrović R, Jakovac H, Tomac J, Šain I. Liver fibrosis in mice induced by carbon tetrachloride and its reversion by luteolin. Toxicol Appl Pharmacol. 2009;241:311-21.

\section{Submit your next manuscript to BioMed Central and we will help you at every step:}

- We accept pre-submission inquiries

- Our selector tool helps you to find the most relevant journal

- We provide round the clock customer support

- Convenient online submission

- Thorough peer review

- Inclusion in PubMed and all major indexing services

- Maximum visibility for your research

Submit your manuscript at

www.biomedcentral com/submit 